\title{
Metabolic follow-up of a Croatian patient with gyrate atrophy and a new mutation in the OAT gene: a case report
}

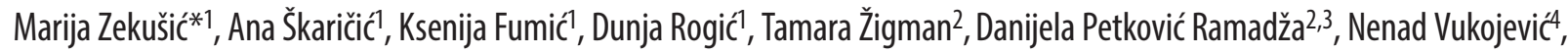 \\ Véronique Rüfenacht ${ }^{5}$, Valentina Uroić, ${ }^{6}$, Ivo Barić2,3 \\ ${ }^{1}$ Department of Laboratory Diagnostics, University Hospital Center Zagreb, Zagreb, Croatia \\ ${ }^{2}$ Department of Pediatrics, University Hospital Center Zagreb, Zagreb, Croatia \\ ${ }^{3}$ School of Medicine, University of Zagreb, Zagreb, Croatia \\ ${ }^{4}$ Department of Ophthalmology, University Hospital Center Zagreb, Zagreb, Croatia \\ ${ }^{5}$ Division of Metabolism, University Children's Hospital, Zürich, Switzerland \\ ${ }^{6}$ Department of Nutrition and Dietetics, University Hospital Center Zagreb, Zagreb, Croatia \\ *Corresponding author: mzekusic@kbc-zagreb.hr
}

\begin{abstract}
Gyrate atrophy (GA) of the choroid and retina is a rare autosomal recessive disorder that occurs due to deficiency of the mitochondrial enzyme ornithine aminotransferase (OAT). Hyperornithinemia causes degeneration of the retina with symptoms like myopia, reduced night vision and progressive vision loss. Our patient is a 10-year-old girl with impaired vision and strabismus. As part of the metabolic work-up, plasma amino acid analysis revealed significantly increased concentration of ornithine $(1039 \mu \mathrm{mol} / \mathrm{L}$; reference interval $20-155 \mu \mathrm{mol} / \mathrm{L})$. Molecular genetic analysis revealed homozygous mutation in exon 7 of the OAT gene that has not been reported previously (c.868_870delCTT p.(Leu290del)). This in frame deletion was predicted to be deleterious by in silico software analysis. Our patient was treated with pyridoxine (vitamin $B_{6}$ in a dose of $2 \times 100 \mathrm{mg} /$ day), low-protein diet $(0.6 \mathrm{~g} / \mathrm{kg} / \mathrm{day})$ and L-lysine supplementation which resulted in a significant reduction in plasma ornithine concentrations to $53 \%$ of the initial concentration and the ophthalmologic findings showed significant improvement. We conclude that low protein diet and lysine supplementation can lead to long-term reduction in plasma ornithine concentrations and, if started at an early age, notably slow the progression of retinal function loss in patients with GA. The effect of therapy can be reliably monitored by periodical measurement of plasma ornithine concentration. To our knowledge, this is the first report of OAT deficiency in Croatia.
\end{abstract}

Keywords: ornithinemia; amino acids; tandem mass spectrometry

\section{Introduction}

Gyrate atrophy (GA) of the choroid and retina (OMIM: 258870) is an inherited disorder of ornithine metabolism characterized by slowly progressive vision loss (1). This condition is caused by mutations in the ornithine aminotransferase (OAT) gene and is inherited in an autosomal recessive manner, resulting in significantly reduced activity of mitochondrial enzyme ornithine aminotransferase (OAT; EC 2.6.1.13) (2). As a consequence, patients have markedly elevated concentrations of ornithine (10 to 15 times higher than normal) in plasma and other body fluids (3). Ornithine ami- notransferase utilizes pyridoxal 5-phosphate, an active form of vitamin $B_{6}$ as a co-factor and is expressed in most tissues, including kidney, small intestine, liver, and retina (4).

The OAT gene analysis is helpful for diagnosing patients with suspected GA. This gene encodes the mitochondrial enzyme OAT which is a key enzyme in the pathway that converts arginine (Arg) and ornithine (Orn) into glutamate (Glu) (5). The OAT protein is coded by a single gene, located on chromosome 10 , region q26 (6). The primary transcript of the OAT gene is $21 \mathrm{~kb}$ long and contains 11 exons 
(7). Translation starts in exon 3 and seems to occur on free polysomes (8). To date, 68 pathogenic mutations have been identified on ClinVar's website, plus 36 likely pathogenic, 25 of uncertain significance, 3 likely benign and 4 benign mutations (9).

The clinical manifestation of GA usually starts with deterioration in visual acuity and night vision, followed by the appearance of sharply demarcated, circular areas of chorioretinal atrophy with hyperpigmented margins in the midperiphery of the fundus (10). During the second and third decade of life the areas of atrophy enlarge and the ocular damage becomes irreversible. By the end of the second decade, most patients with GA develop cataract (11). These progressive vision changes usually lead to blindness in the fifth or sixth decade of life. The exact mechanism of chorioretinal degeneration remains unknown but it is believed to be due to a toxic effect of ornithine or one of its metabolites. Gyrate atrophy is a genetic disorder with increased incidence in Finland, estimated at 1:50,000 (10). Treatment options include dietary supplements and/or a specialized diet. The main source of Orn is dietary Arg, and restriction of Arg in the diet appears to have a therapeutic effect (12).

The aim of this case report is to present the followup of treatment of a 10-year-old girl with GA and points out the importance of regular measuring of amino acid concentrations during the patient's follow-up.

\section{Materials and methods}

\section{Subject}

Here we present a case of a 10-year-old girl with $\mathrm{GA}$ and bilateral cystoid macular oedema. First symptoms in our patient appeared at the age of four when she experienced partial vision loss and strabismus in General Hospital Pula, Croatia. No other family member has reported any eye problems and her parents were both healthy and unrelated. At the age of six years, large retinal atrophic area was observed and GA of the choroid and retina was suspected. Because of this characteristic ophthalmologic finding, she was further evaluated in the University Hospital Centre Zagreb, Croatia under suspicion of OAT deficiency. Ophthalmologic findings, optical coherence tomography (Copernicus, Optopol Technologies, Zawierci, Poland) and fluorescein angiography (Visucam 500, Carl Zeiss Meditec, Jena, Germany) revealed bilateral macular oedema, with numerous circular sharply limited atrophic zones in the retina (Figure 1). Therapy with systemic corticosteroids and topical carbonic anhydrase inhibitors was administered. Further diagnostic workup by a psychologist showed significant attention-deficit with normal intellectual functioning. Signed informed consent was obtained from the patient's parents.

\section{Therapy}

The therapy was divided into three phases. During the first phase, pyridoxine was given at the dose of

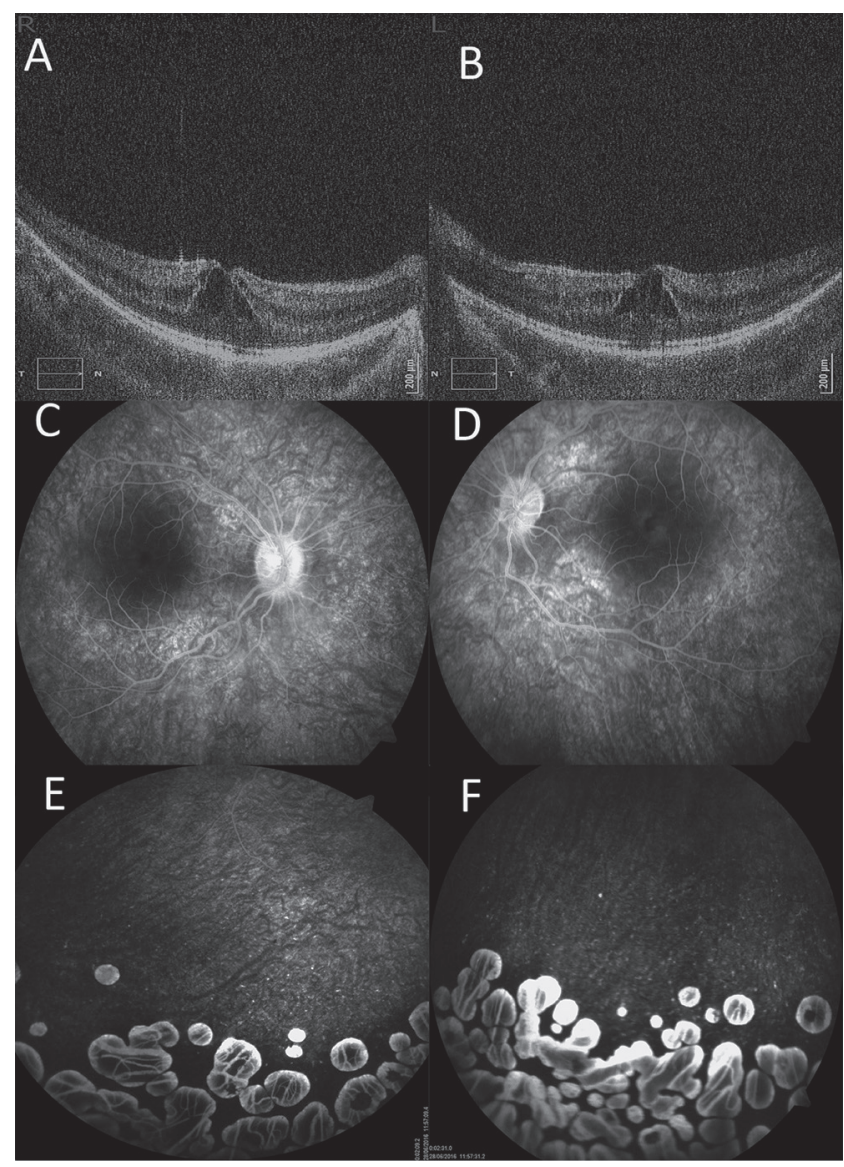

Figure 1. Bilateral cystoid macular oedema - optical coherence tomography $(A, B)$, fluorescein angiography $(C, D)$ and peripheral fundus with numerous circular sharply limited atrophic zones in the retina - fluorescein angiography $(E, F)$. 
$500 \mathrm{mg}$ daily with unsatisfactory clinical and biochemical effect. Plasma Orn concentration was measured at two-month intervals while the patient was fasting. In the second phase of therapy, the dose of pyridoxine was lowered to $2 \times 100 \mathrm{mg}$ daily and a low protein diet was implemented (at first, $1 \mathrm{~g} / \mathrm{kg} /$ day of natural protein that was further gradually lowered to $0.6 \mathrm{~g} / \mathrm{kg} /$ day). Lastly, during the third phase of treatment, the amino acid L-lysine was additionally administered. L-lysine was given in rising dosages from 6 to $12 \mathrm{~g}$ daily. The goal was to increase the excretion of Orn and Arg by urine in order to reduce plasma Orn concentration as low as possible.

\section{Sample collection}

Whole blood was taken on two different anticoagulants, $\mathrm{K}_{3} / \mathrm{K}_{2}$-EDTA and lithium heparin, and in serum gel tubes (Greiner Bio-One $\mathrm{GmbH}^{\circledR}$, Kremsmünster, Austria). For ammonia measurement, samples were collected and immediately put on ice after venepuction. Plasma and serum were removed from the cells by centrifugation at $2500 \mathrm{xg}$ for 10 minutes at room temperature (Thermo Scientific ${ }^{\mathrm{TM}}$, Osterode, Germany) within a few hours after blood collection and analysed immediately. Samples for amino acid analyses were taken in $5 \mathrm{~mL}$ tubes about four hours after meals. Urine samples were collected in $10 \mathrm{~mL}$ tubes without additives (Greiner BioOne $\mathrm{GmbH}^{\circledR}$, Kremsmünster, Austria).

\section{Biochemical and haematological analysis}

Before starting therapy, complete blood count was performed using UniCel ${ }^{\circledR}$ DxH 800 Coulter $^{\circledR}$ analyser (Beckman Coulter Inc., Brea, CA, USA). For routine biochemical analyses, Cobas c501/c311 (Roche Diagnostics ${ }^{\circledR}$, Basel, Switzerland) was used.

\section{Quantitative amino acid analysis}

Amino acids were measured with liquid chromatography coupled with electrospray tandem mass spectrometry LC-MS/MS (UPLC Nexera, Shimadzu, Canby, OR, USA; API 3200, Sciex, Framingham, MA, USA). The use of aTRAQ ${ }^{\mathrm{TM}}$ kit for physiological amino acid analysis (Sciex, Framingham, MA, USA) al- lows quantitation of free amino acids in plasma and urine. Cliquid Software in conjunction with Analyst ${ }^{\oplus}$ Software (Sciex) applications was used to obtain data for the quantification of up to $45 \mathrm{ami}$ no acids. The instrument automatically calculates the concentration of amino acids in each sample. The values obtained from the urine sample must be divided by the creatinine concentration (mmol/ mol creatinine).

Preparation of the samples was made according to manufacturer's instructions using $40 \mu \mathrm{L}$ of physiological fluids. They were introduced firstly into a liquid chromatographic system where they were separated on a chromatographic column (AAA C18 Column, 4.6x150 mm, Sciex, Framingham, MA, USA), and then into a mass spectrometer where they were ionized, fragmented and further separated. The ionized fragments were detected based on mass and ion charge ratio $(\mathrm{m} / \mathrm{z})$. Every ionized fragment generated was characterized by specific retention time. The individual amino acids were identified by characteristic fragments with specific mass transitions (m/z), while the quantitative analysis was performed by comparing the intensity of the patient amino acid ion with the corresponding internal standard (amino acid concentration) (Figure 2).

\section{Molecular genetic analysis}

In order to confirm the diagnosis, a DNA sample of the patient was analysed in a collaborative laboratory (Division of Metabolism, University Children's Hospital, Zürich, Switzerland). Genomic DNA was extracted from $1 \mathrm{~mL}$ whole blood using FlexiGene DNA Kit (Qiagen, Crawley, UK). Polymerase chain reaction (PCR) was carried out using the HotStar Taq DNA Polymerase kit (Qiagen, Hombrechtikon, Switzerland) on a Biometra T-Professional thermocycler (Biometra GmbH, Göttingen, Germany) with following cycling conditions: 1 cycle of $15 \mathrm{~min}$ at $95^{\circ} \mathrm{C}$, followed by 35 cycles of $30 \mathrm{sec}$ at $95^{\circ} \mathrm{C}, 20$ sec at $63^{\circ} \mathrm{C}$ and $1 \mathrm{~min}$ at $72^{\circ} \mathrm{C}$, and finishing with 7 min incubation at $72^{\circ} \mathrm{C}$. The OAT coding exons including the flanking intronic regions were amplified by PCR using the following primers (Table 1). The size and quality of DNA fragments obtained was analysed by $2 \%$ agarose-gel-electrophoresis with EZ Vision One dye (VWR Amresco, Dietikon, 
A

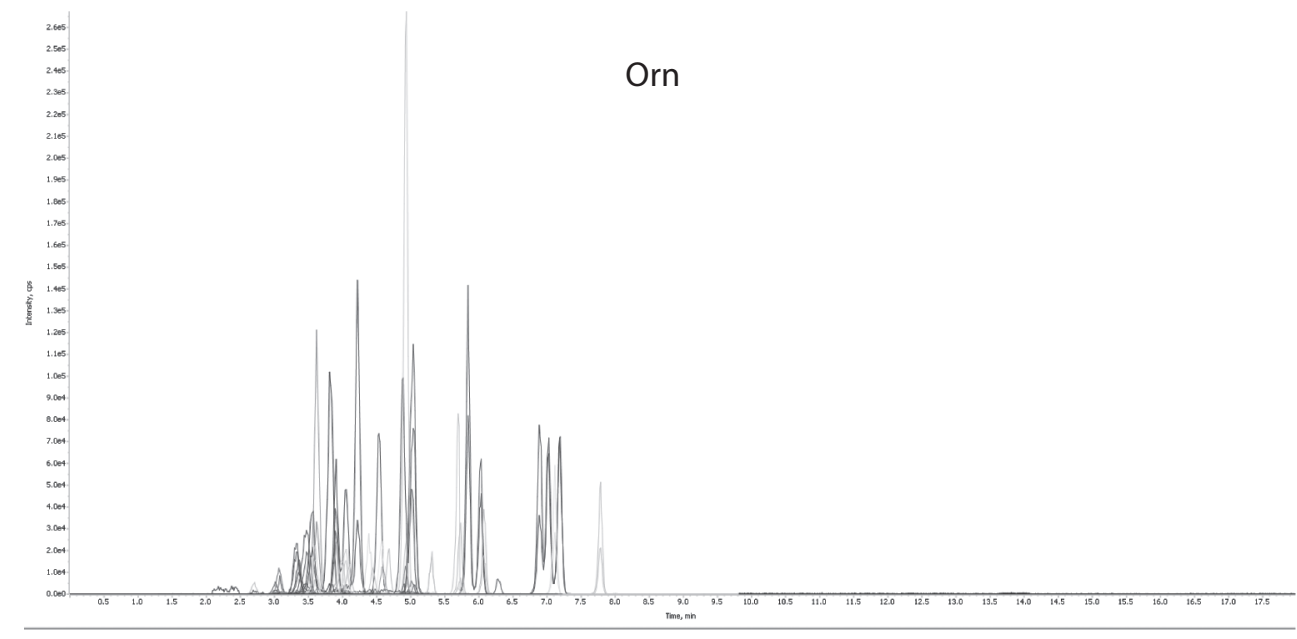

B



FIGURE 2. High intensity peak of ornithine (Orn) was found by comparing the patient's plasma amino acid chromatogram (A) with a chromatogram of the internal standard (B)

Switzerland) in $5 \times$ TBE buffer ( $45 \mathrm{mM}$ Tris-borate, $1 \mathrm{mM}$ EDTA) at $100 \mathrm{~V}$ for 35 minutes. DNA fragments were visualized using the Alphalmager HP gel imaging system (Bio-Techne AG, Zug, Switzerland) under UV light wavelength of $365 \mathrm{~nm}$. After agarose gel electrophoresis PCR products were

TABLE 1. Primer sequences

Exon Primer (5'----3')

\section{Forward}

Exon 2 Fwd 5'-GTGATGGAGTCTTGCTCTGTTGC-3'

Exon 3/4 Fwd 5'-GTGTGTTTTGAAGCTGGGCAG-3',

Exon 5 Fwd 5'-GAAGGTGCACTAAAGCAAGCC-3',

Exon 6 Fwd 5'-GGCAGTGAATTTGAAGTCAG-3',

Exon 7 Fwd 5'-GAGGGCACATCAGAATTACAC-3',

Exon 8 Fwd 5'-GAGTCCAGGAGGCAGAGATTG-3',

Exon 9 Fwd 5'-GCAAGACTCTGAGCTAGTGTATG-3',

Exon 10 Fwd 5'-CAATCTCTTGACCTCGTGATCC-3',

\section{Reverse}

Exon 2 Rev 5'-CCATGTCTGCAATATACAC-3', Exon 3/4 Rev 5'-GAAGGCTGGTCTTGAACTCCAG-3', Exon 5 Rev 5'-GAGAACAAGTCTGAAATCGTGGC-3', Exon 6 Rev 5'-GCTCTTAGAATGCCATCGC-3', Exon 7 Rev 5'-AGGCACACTCAATTCTTCAG-3', Exon 8 Rev 5'-GAGGAAATCCAGTCTACTAGG-3', Exon 9 Rev 5'-CTGAGGCAGAGAATTGCTTG-3', Exon 10 Rev 5'-CGGCAGGTTCATAAACGTTG-3'. 
Sanger sequenced according to standard protocols using the BigDye Terminator Cycle Sequencing kit v1.1 and an ABI 3130 Genetic Analyser (Applied Biosystems by Life Technologies Europe BV, Zug, Switzerland). Sequencing raw data were analyzed using the SeqPatient module of the SEQUENCE PILOT software (JSI Medical Systems, Ettenheim, Germany) using the following reference sequences: OAT Ensembl ENSG00000065154 and ENST00000368845.5. Nomenclature of the mutation follows the recommendations of the $\mathrm{Hu}$ man Genome Variation Society (13) and was checked using the online software Mutalyzer (14).

\section{Results}

Routine biochemical analysis and complete blood count results were within normal range (Table 2), except creatinine and ammonia that were below normal range (creatinine $23 \mu \mathrm{mol} / \mathrm{L}$, reference interval 25 - $42 \mu \mathrm{mol} / \mathrm{L}$; ammonia $20.9 \mu \mathrm{mol} / \mathrm{L}$, reference interval $24.0-48.0 \mu \mathrm{mol} / \mathrm{L}$ ).

Quantitative analysis of amino acids in plasma is necessary for patients suspected to have hyperornithinemia. Our patient had significantly increased initial concentrations of Orn (1039 $\mu \mathrm{mol} / \mathrm{L}$; reference interval 20 - $155 \mu \mathrm{mol} / \mathrm{L}$ ) (Table 3).

During the first phase of therapy, laboratory results of quantitative analysis of amino acids showed only a discrete decline in Orn concentration (13\%). In the second phase of therapy, the decrease of plasma Orn was more significant (48\%). The decrease of bilateral cystoid macular oedema was transient and the progression of peripheral atrophic lesions continued. During the third phase of treatment, adequate reduction of plasma Orn was achieved (53\%) (Figure 3).

This resulted in increase of plasma lysine (Lys) concentration over the next two years from 74 to 218 $\mu \mathrm{mol} / \mathrm{L}$ (reference interval 50 - $284 \mu \mathrm{mol} / \mathrm{L}$ ) (Table 3).

Ornithine excretion in urine was measured at fourmonth intervals. Adding L-lysine supplement to a low protein diet resulted in increased excretion of Orn $(153 \mathrm{mmol} / \mathrm{mol}$ creatinine, reference interval 0 - 7), Arg (36 mmol/mol creatinine, reference interval 0 - 7) and several other amino acids such as as-
TABLE 2. Patient's biochemistry and complete blood count test results

\begin{tabular}{|c|c|c|c|}
\hline Analyte & Results & Unit & $\begin{array}{c}\text { Reference } \\
\text { interval }\end{array}$ \\
\hline Urea & 3.0 & $\mathrm{mmol} / \mathrm{L}$ & $1.8-6.0$ \\
\hline Creatinine & 23 & $\mu \mathrm{mol} / \mathrm{L}$ & $25-42$ \\
\hline Ammonia & 20.9 & $\mu \mathrm{mol} / \mathrm{L}$ & $24.0-48.0$ \\
\hline $\mathrm{K}$ & 4.7 & $\mathrm{mmol} / \mathrm{L}$ & $3.6-5.0$ \\
\hline $\mathrm{Na}$ & 137 & $\mathrm{mmol} / \mathrm{L}$ & $134-143$ \\
\hline $\mathrm{Cl}$ & 102 & $\mathrm{mmol} / \mathrm{L}$ & $96-109$ \\
\hline $\mathrm{Ca}$ & 2.41 & $\mathrm{mmol} / \mathrm{L}$ & $2.15-2.80$ \\
\hline $\mathrm{P}$ & 1.35 & $\mathrm{mmol} / \mathrm{L}$ & $1.11-1.73$ \\
\hline $\mathrm{Mg}$ & 0.77 & $\mathrm{mmol} / \mathrm{L}$ & $0.65-1.03$ \\
\hline Albumin & 47.2 & $g / L$ & $35.0-52.0$ \\
\hline Transferrin & 2.38 & $g / L$ & $2.00-3.60$ \\
\hline $\mathrm{RBC}$ & 4.58 & $\times 10^{12} / \mathrm{L}$ & $4.00-5.00$ \\
\hline $\mathrm{Hb}$ & 127 & $g / L$ & $109-138$ \\
\hline $\mathrm{Hct}$ & 0.373 & $\mathrm{~L} / \mathrm{L}$ & $0.320-0.404$ \\
\hline MCV & 78.3 & $\mathrm{fL}$ & $73.8-89.4$ \\
\hline $\mathrm{MCH}$ & 26.8 & $\mathrm{pg}$ & $24.3-29.2$ \\
\hline $\mathrm{MCHC}$ & 342 & $g / L$ & $300-350$ \\
\hline RDW & 14.1 & $\%$ & $9.0-15.0$ \\
\hline Rtc & 9.1 & $/ 1000 \mathrm{RBC}$ & $4.0-19.0$ \\
\hline Rtc & 43 & $\mathrm{x} 10^{9} / \mathrm{L}$ & $22-97$ \\
\hline IRF & 0.3 & & $0.1-0.3$ \\
\hline WBC & 5.4 & $\times 10^{9} / \mathrm{L}$ & $5.0-13.0$ \\
\hline Eosinophils & 3 & $\%$ & $0-6$ \\
\hline $\begin{array}{l}\text { Segmented } \\
\text { Neutrophils }\end{array}$ & 51 & $\%$ & $30-72$ \\
\hline Lymphocytes & 33 & $\%$ & $15-55$ \\
\hline Monocytes & 13 & $\%$ & $5-13$ \\
\hline Eosinophils & 0.16 & $\mathrm{x} 10^{9} / \mathrm{L}$ & $0.00-0.70$ \\
\hline $\begin{array}{l}\text { Segmented } \\
\text { Neutrophils }\end{array}$ & 2.75 & $\times 10^{9} / L$ & $1.40-8.00$ \\
\hline Lymphocytes & 1.78 & $\mathrm{x} 10^{9} / \mathrm{L}$ & $1.40-5.00$ \\
\hline Monocytes & 0.70 & $\mathrm{x} 10^{9} / \mathrm{L}$ & $0.22-1.51$ \\
\hline PLT & 198 & $\mathrm{x} 10^{9} / \mathrm{L}$ & $150-450$ \\
\hline MPV & 8.9 & $\mathrm{fL}$ & $6.9-11.3$ \\
\hline
\end{tabular}

$\mathrm{K}$ - potassium. $\mathrm{Na}$ - sodium. $\mathrm{Cl}$ - chloride. $\mathrm{Ca}$ - calcium. $\mathrm{P}$ inorganic phosphates. $\mathrm{Mg}$ - magnesium.RBC - red blood cell count. $\mathrm{Hb}$ - haemoglobin. Hct - haematocrit. RDW - red cell distribution width. MCV - mean corpuscular volume. $\mathrm{MCH}$ mean corpuscular haemoglobin. MCHC - mean corpuscular haemoglobin concentration; Rtc - reticulocytes. IRF immature reticulocytes fraction. WBC - white blood cell count. MPV - mean platelet volume. PLT - platelet count. 
TABLE 3. Long-term follow-up: plasma amino acids in the patient with gyrate atrophy

\begin{tabular}{|c|c|c|c|c|c|}
\hline \multirow[b]{2}{*}{ Amino acids } & \multirow[b]{2}{*}{$\begin{array}{c}\text { Reference } \\
\text { interval ( } \mu \mathrm{mol} / \mathrm{L})\end{array}$} & \multirow[b]{2}{*}{$\begin{array}{l}\text { Before treatment } \\
(\mu \mathrm{mol} / \mathrm{L})\end{array}$} & \multicolumn{3}{|c|}{ After treatment ( $\mu \mathrm{mol} / \mathrm{L})$} \\
\hline & & & $\begin{array}{l}\text { First phase (vit. } B_{6} \\
500 \mathrm{mg} / \text { day) }\end{array}$ & $\begin{array}{l}\text { Second phase (vit. } \\
B_{6} 200 \mathrm{mg} / \text { day and } \\
\text { low-protein diet) }\end{array}$ & $\begin{array}{c}\text { Third phase (vit. }{ }_{6} 200 \\
\text { mg/day, low-protein } \\
\text { diet and L-lysine) }\end{array}$ \\
\hline Orn & $20-155$ & 1039 & 907 & 537 & 489 \\
\hline Ala & $130-547$ & 250 & 229 & 506 & 642 \\
\hline Arg & $10-140$ & 79 & 81 & 66 & 58 \\
\hline Asn & $20-112$ & 47 & 47 & 53 & 49 \\
\hline Asp & $0-20$ & 4 & 4 & 4 & 4 \\
\hline Cit & $1-46$ & 31 & 31 & 23 & 26 \\
\hline Gln & $254-823$ & 518 & 637 & 568 & 629 \\
\hline Glu & $10-150$ & 21 & 17 & 18 & 16 \\
\hline Gly & $110-343$ & 194 & 163 & 251 & 199 \\
\hline His & $41-125$ & 63 & 68 & 78 & 87 \\
\hline Hyp & $0-45$ & 26 & 28 & 21 & 15 \\
\hline Ile & $22-107$ & 61 & 68 & 43 & 39 \\
\hline Leu & $49-216$ & 110 & 125 & 75 & 75 \\
\hline Lys & $50-284$ & 74 & 72 & 201 & 218 \\
\hline Met & $15-45$ & - & 0 & - & 23 \\
\hline Phe & $26-91$ & 46 & 51 & 47 & 40 \\
\hline Pro & $60-340$ & 166 & 202 & 207 & 187 \\
\hline Ser & $70-194$ & 141 & 133 & 164 & 112 \\
\hline Tau & $20-170$ & 32 & 30 & 48 & 40 \\
\hline Thr & $35-226$ & 134 & 135 & 94 & 86 \\
\hline Tyr & $25-115$ & 58 & 65 & 51 & 36 \\
\hline Val & $80-321$ & 209 & 216 & 164 & 131 \\
\hline
\end{tabular}

Orn - ornithine. Ala - alanine. Arg - arginine. Asn - asparagine. Asp - aspartic acid. Cit - citrulline. Gln - glutamine. Glu - glutamic acid. His - histidine. Hyp - hydroxyproline. Ile - isoleucine. Leu - leucine. Lys - lysine. Met - methionine. Phe - phenylalanine. Pro proline. Ser - serine. Thr - threonine. Tyr - tyrosine. Val - valine.

paragine (Asn) $(203 \mathrm{mmol} / \mathrm{mol}$ creatinine, reference interval 0 - 29), Lys $(235 \mathrm{mmol} / \mathrm{mol}$ creatinine, reference interval $10-68$ ), and citrulline (Cit) (9 $\mathrm{mmol} / \mathrm{mol}$ creatinine, reference interval 0 - 5) in urine. In the third period during treatment with $\mathrm{L}-$ lysine, urinary excretion of Orn was highly increased. Administration of L-lysine increased renal excretion of Arg and Orn, which contributed to a decrease of plasma Orn.

The reduction of plasma Orn was associated with a positive change in the patient's electroretinograms. During the third phase of therapy, the oph- thalmologic fundus examination showed significant improvement (only discrete oedema of the macula was found).

Molecular genetic analysis revealed the homozygous mutation c.868_870delCTT in the exon 7 of the OAT gene resulting in the deletion of one amino acid p.(Leu290del). So far, this mutation has not been described in the Human Gene Mutation Database. The mutation (in frame deletion) was predicted to be pathogenic by in silico software: PROVEAN (Protein Variation Effect Analyser): score $=-10.25$ (cut-off $=-2.5$ ), prediction: deleterious. 


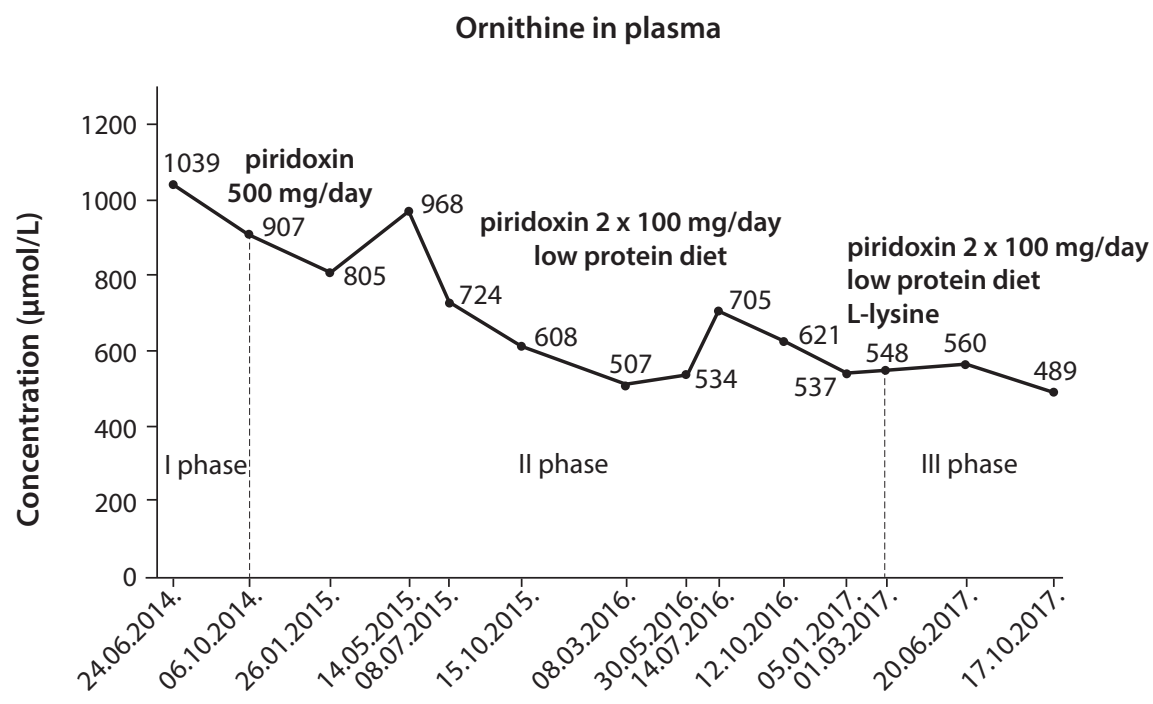

Figure 3. Monitoring of plasma amino acid concentration during dosage adjustment. Ornithine values significantly differed between the first and third period of treatment.

\section{Discussion}

Hyperornithinemia causes a permanent loss of retinal cells (atrophy) with the symptoms like myopia and progressive deterioration of peripheral and night vision, eventually resulting in blindness (1). Most patients with a diagnosis of GA have no symptoms other than vision loss, but in some cases neonatal hyperammonemia, intellectual disability, peripheral nerve problems and muscle weakness may occur (15). Our patient did not have any additional symptoms besides vision loss.

Besides high Orn concentration, low plasma concentrations of Lys, Glu, ammonia and creatinine are common characteristics of untreated GA (1). Our patient had mildly decreased concentrations of Lys and Glu (close to the lower reference limit). Plasma ammonia and creatinine were also reduced (below the reference interval). The reason for decreased concentration of ammonia and glutamate in untreated patients with GA is unknown.

An ordinary diet usually contains a high amount of protein, including amino acid Arg. However, Arg is an essential amino acid in GA patients and limitation of dietary Arg might result in reduction of plasma and urine Orn (16). The reduction of Arg intake had only transient benefit in our patient. The most benefit was achieved when L-lysine was added to the treatment. The dose of L-lysine was gradually increased until a plateau in ornithine plasma concentration was reached. In the study of Elpeleg et al. the administration of 10 - $15 \mathrm{~g}$ L-lysine daily for 40 - 55 days in three patients (ages 13 - 19) with gyrate atrophy decreased plasma Orn concentrations by 21 - 31\%. A daily dose of $15 \mathrm{~g}$ was more effective than $10 \mathrm{~g}$ (17). It has been described in the literature that less than $5 \%$ of patients with GA had been responsive to vitamin $B_{6}(1,18,19)$. A slight decrease in plasma Orn concentration was observed after supplementing vitamin $B_{6}$ in our patient.

Recently, a new diagnostic test based on proline/ citrulline ratio (Pro/Cit) in plasma and dried blood spot (DBS) in new-born screening laboratories was developed $(20,21)$. Deficiency of OAT causes an increase in Pro/Cit ratio. Ornithine and Arg concentrations in plasma/DBS are often abnormal in neonates with OAT deficiency (Pro is increased, Cit is reduced) $(21,22)$. This theory supports the use of the Pro/Cit ratio on tandem mass spectrometry with the best diagnostic sensitivity and accuracy. Proline/citrulline ratio should be considered as a differential diagnostic tool in new-born screening 
allowing differential diagnosis for all new-borns with hyperammonemia suspected of OAT deficiency (22). However, we have no possibility of verifying that information for our GA patient because our new-born screening laboratory in Croatia stores DBS for only five years. Current medical literature is lacking in data on early introduction of therapy in patients detected by new-born screening and patient's follow-up. The reason for that could be relatively low disease incidence and probably low detection rate in less developed countries.

Patients with GA generally have normal intelligence (23). One of described patients had mild mental retardation, delayed language development, and speech defects (24). Our 10-year-old patient had normal intellectual functioning but with significant attention-deficit.

Hyperornithinemia is the main pathogenic factor in GA and our case proves that it can be treated by low protein diet, supplementation of vitamin $B_{6}$ and L-lysine. To the best of our knowledge, this is the first report of GA in Croatian population. For the first time we introduce an approach of a stepwise L-lysine dosage adjustment guided by regular plasma Orn quantification, which resulted in the highest plasma ornithine reduction reported in the literature. The diagnosis was confirmed by molecular genetic analysis, with a new homozygous mutation detected in the OAT gene.

The purpose of this paper was to stress the importance of early diagnostics and treatment in GA. Laboratory professionals together with clinicians should consider introduction of new Pro/Cit ratio test in new-born screening programs since it could be valuable for the early diagnosis and treatment of GA patients, thus preventing occurrence of irreversible retinal changes.

It should be acknowledged that there are several limitations in this case report. The follow-up period is relatively short to show long-term outcome of the treatment on patient's vision, although ophtalmological follow-up did show promising results.
This is a follow-up study of only one patient. A larger number of treated patients might give us better insight into the efficacy of this treatment approach. As the disease is very rare (approximately 150 individuals with GA have been identified so far) multicentre collaboration would be needed to achieve that (18). For improvement of this study it should be useful to screen more subjects. The introduction of new-born screening for OAT deficiency should be helpful in early detection and early treatment introduction. Our patient is homozygous for a previously undescribed mutation expected to be pathogenic due to clear clinical phenotype (pathognomonic ocular changes), quantitative amino acid analysis and in silico analysis. For final proof of pathogenicity, further functional studies are needed to validate our results. As parental DNA was unavailable, we examined only our patient; consequently, it is not certain if this mutation is de novo mutation. Finally, Sanger sequencing by capillary electrophoresis was used. It is currently the most widely used routine molecular analysis and is adequate for the majority of clinical applications involving the analysis of single genes. The method is rapid, robust and known as a gold standard for clinical research sequencing with $99.9 \%$ accuracy, so it was not necessary to confirm this mutation with a second different molecular analysis (25).

In conclusion, if therapy for GA is introduced at an early age, along with long-term monitoring of plasma Orn concentrations, the progression of retinal function loss may be notably delayed. Combined treatment with low protein diet, L-lysine and pyridoxine supplementation in our patient resulted in plasma Orn decrease to $53 \%$ of the initial concentration and a significant improvement of ocular changes. Although longer follow-up is needed to estimate true benefits of this treatment, we find results presented in this paper very encouraging.

\section{Potential conflict of interest}

None declared. 


\section{References}

1. Valle $D$, Simell O. The hyperornithinemias. In: Scriver $C R, B e-$ audet $A L$, Sly WS, eds. The metabolic and molecular bases of inherited disease. New York: McGraw-Hill; 2001. p.1875-95.

2. Takki K, Simell O. Genetic aspects in gyrate atrophy of the choroid and retina with hyperornithinaemia. Br J Ophthalmol. 1974;58:907-16. https://doi.org/10.1136/bjo.58.11.907

3. Kaiser-Kupfer MI, Ludwig IH, de Monasterio FM, Valle D, Krieger I. Gyrate atrophy of the choroid and retina. Early findings. Ophthalmology. 1985;92:394-401. https://doi. org/10.1016/S0161-6420(85)34022-8

4. Ohkubo Y, Ueta A, Ito T, Sumi S, Yamada M, Ozawa K, Togari H. Vitamin B6-responsive ornithine aminotransferase deficiency with a novel mutation G237D. Tohoku J Exp Med. 2005;205:335-42. https://doi.org/10.1620/tjem.205.335

5. Mitchell GA, Looney JE, Brody LC, Steel G, Suchane M, Engelhardt $J F$, et al. Human ornithine-delta-aminotransferase. cDNA cloning and analysis of the structural gene. J Biol Chem. 1988;263:14288-95.

6. Barrett DJ, Bateman JB, Sparkes RS, Mohandas T, Klisak I, Inana G. Chromosomal localization of human ornithine aminotransferase gene sequences to $10 q 26$ and Xp11. 2. Invest Ophthalmol Vis Sci.1987;28:1037-42.

7. Ramesh V, Eddy R, Bruns GA, Shih VE, Shows TB, Gusella JF. Localization of the ornithine aminotransferase gene and related sequences on two human chromosomes. Hum Genet. 1987;76:121-6. https://doi.org/10.1007/BF00284906

8. Hayashi H, Katunuma N, Chiku K, Endo Y, Natori Y. Cell-free synthesis of ornithine aminotransferase of rat liver. J Biochem. 1981;90:1229-32. https://doi.org/10.1093/oxfordjournals.jbchem.a133577

9. ClinVar. Available at: https://www.ncbi.n/m.nih.gov/clinvar. Accessed April 8th 2018.

10. Takki KK, Milton RC. The natural history of gyrate atrophy of the choroid and retina. Ophthalmology. 1981;88:292-301. https://doi.org/10.1016/S0161-6420(81)35031-3

11. Kaiser-Kupfer M, Kuwabara T, Uga S, Takki K, Valle D. Cataracts in gyrate atrophy: clinical and morphologic studies. Invest Ophthalmol Vis Sci. 1983;24:432-6.

12. Kaiser-Kupfer MI, de Monasterio FM, Valle D, Walser M, Brusilow S. Gyrate atrophy of the choroid and retina: improved visual function following reduction of plasma ornithine by diet. Science. 1980;210:1128-31. https://doi.org/10.1126/ science.7444439

13. Nomenclature by J-T.Den Dunnen. Available at: http://varnomen.hgvs.org/ recommendations/DNA/. Accessed April 8th 2018.
14. Name Checker Mutalyzer 2.0.26. Available at: https://mutalyzer.nl/name-checker. Released on July 19th 2017.

15. Sipilä I, Simell O, Rapola J, Sainio K, Tuuteri L. Gyrate atrophy of the choroid and retina with hyperornithinemia: tubular aggregates and type 2 fiber atrophy in muscle. Neurology. 1979;29:996-1005. https://doi.org/10.1212/WNL.29.7.996

16. Valle D, Walser M, Brusilow SW. Gyrate atrophy of the choroid and retina: amino acid metabolism and correction of hyperornithinemia with an arginine-deficient diet. J Clin Invest. 1980;65:371-8. https://doi.org/10.1172/JCI109680

17. Elpeleg N, Korman SH. Sustained oral lysine supplementation in ornithine delta-aminotransferase deficiency. J Inherit Metab Dis. 2001;24:423-4. https://doi. org/10.1023/A:1010545811361

18. Wirtz MK, Kennaway NG, Weleber RG. Heterogeneity and complementation analysis of fibroblasts from vitamin B6 responsive and non-responsive patients with gyrate atrophy of the choroid and retina. J Inherit Metab Dis. 1985;8:71-4. https://doi.org/10.1007/BF01801668

19. Javadzadeh A, Gharabaghi D. Gyrate atrophy of the choroid and retina with hyper-ornithinemia responsive to vitamin B6: a case report. J Med Case Rep. 2007;1:27. https:// doi.org/10.1186/1752-1947-1-27

20. de Sain-van Der Velden MG, Rinaldo $P$, Elvers $B$, Henderson $M$, Walte $J H$, Prinsen BHCMT, et al. The proline/citrulline ratio as a biomarker for OAT deficiency in early infancy. JIMD Rep. 2012;6:95-9. https://doi.org/10.1007/8904_2011_122

21. Cleary MA, Dorland L, De Koning TJ, Poll-The BT, Duran M, Mandell $R$, et al. Ornithine aminotransferase deficiency: Diagnostic difficulties in neonatal presentation. $J$ Inherit Metab Dis. 2005;28:673-9. https://doi.org/10.1007/s10545005-0074-1

22. Ginguay A, Cynober L, Curis E, Nicolis I. Ornithine aminotransferase, an important glutamate-metabolizing enzyme at the crossroads of multiple metabolic pathways. Biology. 2017;6:18. https://doi.org/10.3390/biology6010018

23. Peltola KE, Jaaskelainen S, Heinonen OJ, Falck B, Nanto-Salonen $K$, Heinanen $K$, Simell O. Peripheral nervous system in gyrate atrophy of the choroid and retina with hyperornithinemia. Neurology. 2002;59:735-40. https://doi. org/10.1212/WNL.59.5.735

24. Stoppoloni G, Prisco F, Santinelli R, Tolone C. Hyperornithinemia and gyrate atrophy of choroid and retina: report of a case. Helv Paediat Acta. 1978;33:429-33.

25. Anderson MW, Schrijver I. Next generation DNA sequencing and the future of genomic medicine. Genes. 2010;1:38-69. https:// doi.org/10.3390/genes1010038 